\title{
Research on Intelligent Tap Testing of Aviation Composite Material
}

\author{
Yanjun Li, Jian Zhang, Jing Zhao and Jiandong $\mathrm{Hu}$ \\ College of Civil Aviation, Nanjing University of Aeronautics and Astronautics, Nanjing 211106, China
}

\begin{abstract}
Composite material is fourth largest aviation materials after the aluminum, steel, titanium and has been widely used in aviation. Defects and damages is inevitable in the process of its production and manufacturing, that seriously hazards the aviation security. Tap testing is the simplest and the most widely used nondestructive testing (NDT) method, but it encountered many problems developing in the direction of intelligent. In this paper, the composite material structural characteristics, defects and damages, security, knock detection principle, knock hammer design, signal processing unit, database building and intelligent detection algorithm were further studied, and the knock detection standard process and specification, database construction methods and intelligent clustering algorithm was put forward. Finally, the intelligent tap testing system is developed based on above research.
\end{abstract}

Keywords-aviation composite material; defects and damages; intelligent knock detection; security; database

\section{INTRODUCTION}

Aviation composite material has the advantages of high specific strength, high stiffness, strong design, good fatigue performance, corrosion resistance, easy to large area overall shape and so on. Its use brings opportunities for civil aircraft design, production and airworthiness and maintenance and has been widely used in the Boeing 777, 787, Airbus A320, A322, A330 and Ann - 124 and other large commercial and numerous medium commercial planes [1].

However, defects and damages exist inevitably in the process of manufacture and use. Defects are usually generated in the manufacturing process and are the innate problems; it derives from some adverse factors in the manufacturing process, such as lax specification, bad quality assurance and testing. Damages happen in the process of use and can be repaired in theory. New aviation composite's high cost, special structure and working environment put forward stricter and targeted test conditions and requirements including cannot use coupling agent, small detection space, large size component, complex structure, and high efficiency detection, real-time and visual results [2].

Tap testing is the most widely used NDT method and has the advantages of simple, cheap, in situ and fast relative to other NDT methods. After a long period of development, the tap testing tool gradually evolved into a smart tap testing system from the original stick and coin [3]. At present, the most popular tap testing tool includes the following three types: PN98A57103013 from Airbus, WP - 632 from Japan's Mitsui, P/NF4TAP002 RD3 Tap Hammer from Boeing.
Based on the research of composite material and intelligent tap testing method, we designed the intelligent tap hammer, formulated the tap testing standard process and specification, built the tap testing signal processing unit and tap testing database by using standard simulation model, proposed intelligent clustering algorithm and finally developed the intelligent tap testing system.

\section{Aviation Composite Material}

\section{A. Characteristics of Aviation Composite Material}

Composite materials using in aviation mainly include fiber reinforced composite materials (CFRP and GFRP, GLARE), sandwich structure composite material (honeycomb sandwich composite materials, foam sandwich composite materials), high temperature resistant composite materials (C/C composites and $\mathrm{C} / \mathrm{SiC}$ composites).Composite material is composed of substrate material and reinforced material, substrate material includes metal, polymer and inorganic nonmetal, reinforced material includes continuous fiber, short fiber, granular packing and knitting.

\section{B. Defects and Damages of Aviation Composite Material}

The defects and damages of composite materials include manufacturing defects, using defects and environmental damages. Typical manufacturing defects include gap, rich or poor glue, foreign inclusions, incorrect fiber orientation and layer sequence, scratches, flawed holes and tight connection, etc. Typical using damages include scratch, edge damages, delamination, degumming, dent and penetrating injury caused by impact, etc. Typical environmental damages include surface ablation and layered caused by lightning shock, wet expansion caused by freezing/melting, layering and degumming caused by thermal shock, layered of the sandwich structure caused by water immersion, etc. Composite material damages extension is the no cumulative rule extension and its combination results of possible matrix cracking, interface debonding, layered and fiber breakage. The lack of regularity makes structure durability and damages tolerance analysis of composite material very difficult [4].

\section{Security of Aviation Composite Material}

The FAA AC20-107A is a systematically and completed material of composite material airworthiness certification. From the security perspective, composite material damages can be divided into three categories: permissive, repairable and unrepairable. Permissive damage refers to the damage or defect that does not need to repair within the design life. Unrepairable damage refers to the damage that is beyond the repairable limit and can only be replaced. Damage tolerance 
mainly study hole, impact damage and layering. The three damage forms are not only representative but also the most serious influence on structure bearing capacity [5].Damage assessment is the basis of composite repair and generally performed in accordance with the following steps: 1) to determine the damages degree; 2) to evaluate damage result from component type, damage type, affects scope and degree; 3 ) to confirm the acceptable damage level.

\section{NONDESTRUCTIVE INTELLIGENT TAP TESTING}

\section{A. NDT Methods}

Defect and damage testing of composite material is the basis and premise of repair and the reference of performance evaluation. NDT method used for aerospace composite mainly includes ray testing, acoustic testing, electricity testing, magnetism testing, optical testing, thermal testing and osmosis testing [6], the specific methods are shown in table 1. Every method has different testing principle, effects and testing objects. When choosing NOT method, the following situation of tested work piece should be considered: 1) space size of installation site and accessibility; 2) property of material;3) Geometry dimension;4) strained condition in use;5) surface condition of the work piece [7].

TABLE I. NDT METHODS CLASSIFICATION

\begin{tabular}{|l|l|}
\hline \multicolumn{1}{|c|}{$\begin{array}{c}\text { NDT } \\
\text { methods }\end{array}$} & \multicolumn{1}{|c|}{ Specific methods } \\
\hline Ray testing & $\begin{array}{l}\text { X-ray testing, } \gamma \text {-ray testing, neutron-ray testing, ray computer } \\
\text { tomography testing, B-ray and } \gamma \text {-ray thickness measurement } \\
\text { technology }\end{array}$ \\
\hline $\begin{array}{l}\text { Acoustic } \\
\text { testing }\end{array}$ & $\begin{array}{l}\text { Acoustic emission testing, acoustic-ultrasonic testing, } \\
\text { acoustic vibration testing, acoustical holography testing, } \\
\text { acoustic imaging testing, ultrasonic testing, acoustic } \\
\text { microscope testing }\end{array}$ \\
\hline $\begin{array}{l}\text { Electrical } \\
\text { testing }\end{array}$ & $\begin{array}{l}\text { Eddy current testing, the potential difference testing, ac field } \\
\text { testing, electric current perturbation testing, microwave } \\
\text { testing }\end{array}$ \\
\hline $\begin{array}{l}\text { Magnetism } \\
\text { testing }\end{array}$ & $\begin{array}{l}\text { Magnetic particle testing, the leakage magnetic field testing, } \\
\text { metal magnetic memory testing, Barkhausen noise } \\
\text { testing,magnetic-acoustic emission testing }\end{array}$ \\
\hline $\begin{array}{l}\text { Optical } \\
\text { testing }\end{array}$ & $\begin{array}{l}\text { Visual testing, laser holographic dislocation and electronic } \\
\text { speckle interferometry testing, laser speckle testing }\end{array}$ \\
\hline $\begin{array}{l}\text { Thermal } \\
\text { testing }\end{array}$ & \begin{tabular}{l} 
Thermal-optic testing, temperature difference testing \\
\hline $\begin{array}{l}\text { Osmosis } \\
\text { testing }\end{array}$
\end{tabular} $\begin{array}{l}\text { Fluid osmosis testing, fluorescence testing, Coloring osmosis } \\
\text { testing }\end{array}$ \\
\hline
\end{tabular}

\section{B. Principle of Tap Testing}

Traditional tap testing taps structure surface by stick or coin and the operator judges condition through the change of echo; the method depends on the operator. With the introduction of acceleration sensor, tap testing changed from perceptual to rational, from qualitative to quantitative transformation that makes tap testing result more accurate and can be used as a kind of independent composite material testing method. The principle of tap testing is shown in figure 1.

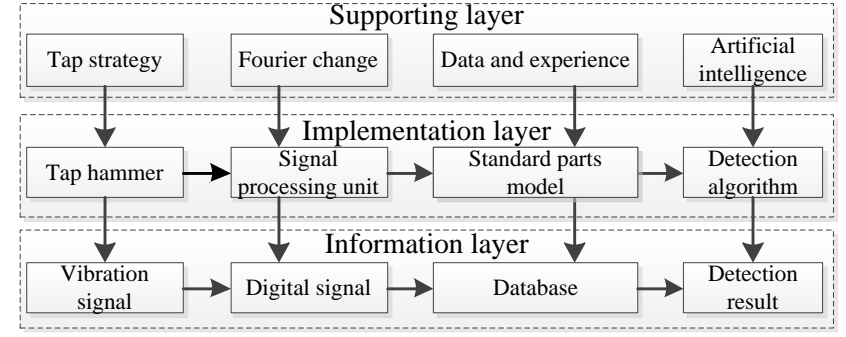

FIGURE I. INTELLIGENT TAP TESTING PRINCIPLE DIAGRAM

Tap hammer collects the vibration signal of the impedance through the acceleration sensor embedded in the hammer head and send the signal to Programmable Logic Array Integrated Circuit (PALIC) in the form of voltage waveform to process and measure the signal. Identify defects or damages by using the intelligent detection algorithm to compare testing data with standard data in the database.

\section{Design of Tap Hammer}

The digital tap hammer designed in this paper is shown in figure 2 .

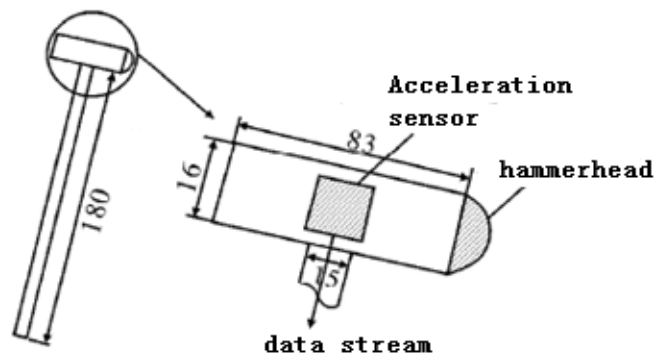

FIGURE II. DIGITAL TAP HAMMER STRUCTURE

Tap strategy is used to assist tap testing, including tap strength, angle, the minimum interval and measures to guarantee the tap comprehensiveness. The following tap strategies were made by experiment analysis: the force acting on the tested surface is about $0.0675 \mathrm{~N}$. Tap angle is perpendicular to tap surface; Minimum hitting interval is $0.5 \mathrm{~s}$, and can be appropriately extended according to different reading ways. Assist testing with artificial marking or laser projection grid meshing method to ensure testing comprehensiveness.

The principle of vibration signals changed into voltage signals is shown in figure 3 . The system is usually composed with sensitive element, conversion element, signal conditioning circuit and auxiliary circuit.

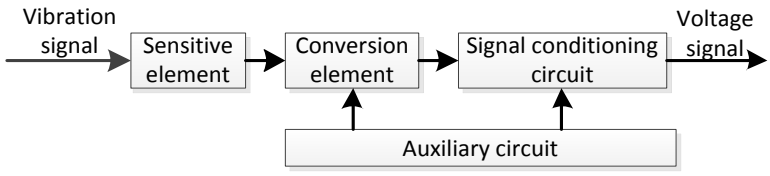

FIGURE III. PRINCIPLE DIAGRAM OF SENSOR

This paper selects the piezoelectric acceleration sensor to collect the initial vibration information; it has the advantages of high fixed frequency, high frequency response, rich 
acceleration measurement range, solid, small, light and wide working temperature range, low cost and the high output voltage.

\section{Signal Processing Unit}

Signal processing is the core of digital tap testing, which directly affects the quality of testing. Tap signal processing unit is shown in figure 4 mainly including amplifier circuit, voltage comparator, adjustable switching voltage stabilizer, FPGA, chip configuration, computer software.

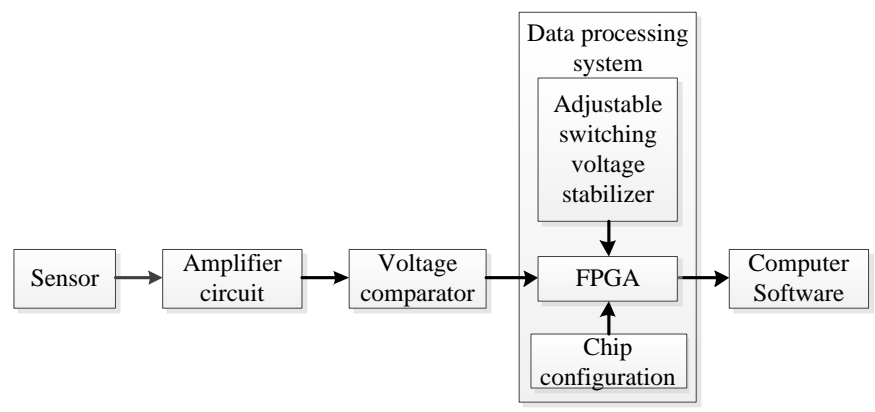

FIGURE IV. SIGNAL PROCESSING UNIT

The signal collected by sensor is very short, continuous and aperiodic. As is shown in figure 5, it firstly needs to be dealt with Fourier transform and then measured with PALIC. The left and right of the figure are respectively normal and damage position testing waveform. The threshold is set in the PAL IC and won't change along with signal. The output of the signal processing unit is the time that waveform exceeds the threshold and the unit is microsecond. If the peak of tap waveform does not reach the threshold set in PALIC, then the digital tap hammer output is 0 . As is shown in the figure, the damage area waveform has longer time above threshold that means the output of digital tap hammer is bigger.

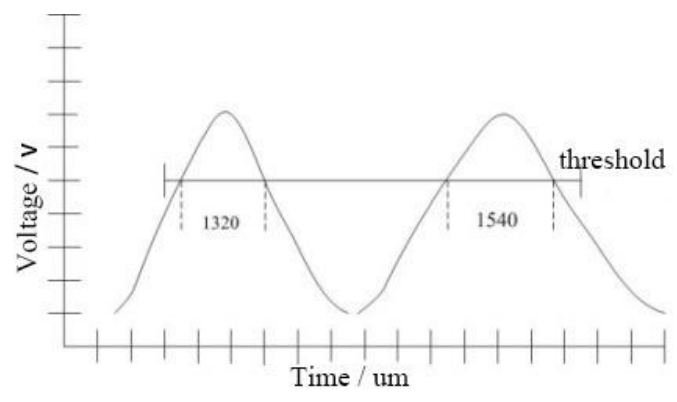

FIGURE V. MEASURING SIGNAL WITH PALIC

The system designed by author chooses LM6134 voltage amplifier, MAX942 hysteresis voltage comparator, MAX639 step-down switching voltage stabilizer, MAX045 quartz crystal oscillator, 1763 EPC configuration chip, XC3030 programmable logic devices.

\section{E. Database}

All states data and its management is needed to identify defects and damages, as a result the tap testing database is established. Make test pieces that meet the following functions to get all states data: 1) can obtain digital tap equipment resolution; 2) can contain common defects and damages of the material; 3)can cover common structure type;
4) with certain structural versatility and are applicable to the test model of various materials. Through theoretical analysis, it is found that general composite material structure includes three types: flat structure, surface structure and reinforcement structure. Therefore, the three kind of typical structures should be included when establishing test pieces and different defects should be built-in to get accurate test results.

Tap testing is the most sensitive to composite material bonding quality, so choosing it to show the test piece making method. Defect built-in is complex. The experiment shows that the feasible methods include bubbles, solid blank and impurity separation, etc. The test piece and its damages distribution are shown in figure6.

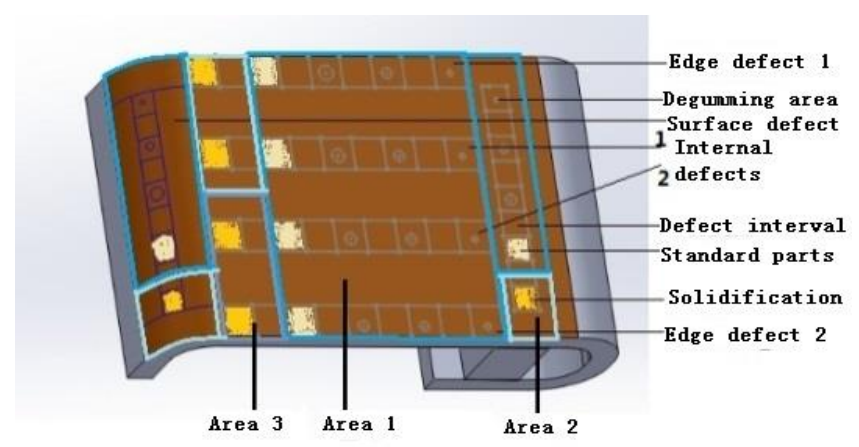

FIGURE VI. TEST PIECES DAMAGES DISTRIBUTION DIAGRAM

\section{F. Intelligent Algorithm}

Testing data and standard data are gained through above method and defects and damages identification can be realized using the following ways: 1) classify samples according to different structure and carried out following steps respectively; 2) cluster the samples and eliminate samples whose number is less than threshold $r$; 3) cluster the rest number with the standard damages sample data as clustering center and the final category is the corresponding damage of the test piece.

\section{INTELLIGENT TAP TESTING SySTEM}

\section{A. Overall Structure}

The intelligent tap testing system for civil aircraft composite structure shown in figure 7 is developed on the above research basis of tap hammer principle and design, signal processing unit, database building and intelligent algorithm. The system includes digital tap hammer, signal processing unit, software system, etc., can be used in the rapid detection and damages evaluation of outfield and ultimately generates testing report. So it supports reference for health monitoring of civil aircraft composite material. 


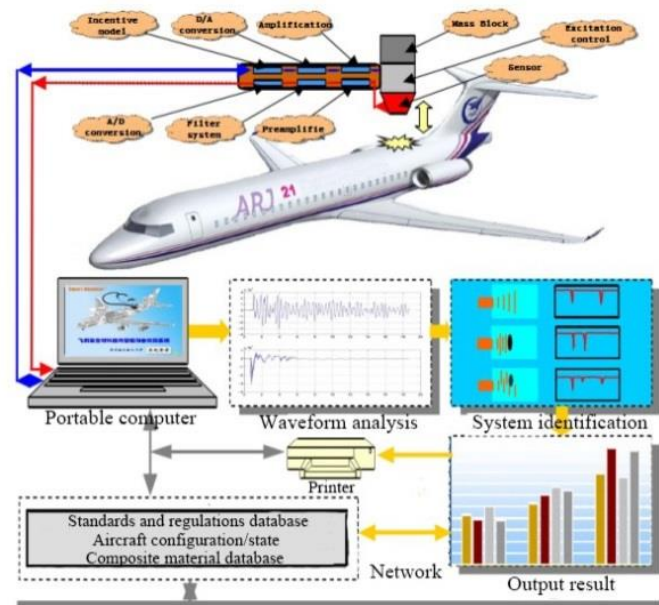

FIGURE VII.

PRINCIPLE DIAGRAM OF TAP NDT SYSTEM

\section{B. Hardware and Software}

The system development tool is $\mathrm{VC}++6.0$, the database is Access 2000. The hardware platform for operation needs above P4 2.0 G CPU, 256M minimum memory, 20 G minimum hard drive space. It needs minimum version Windows 2000 system and Office 2000 tool.

\section{System Function}

The final software main interface is shown in figure 8 and mainly consists of information input, testing, database maintenance, system login and logout. Information input module is used to connect tap hammer for data acquisition and preprocessing. Testing module is used to analyze the data to get defects and damages report and can choose or change the key parameters and intelligent algorithm. Database maintenance module is used to manage standard and history data. System login and logout module are used to manage user registration, permissions, personal information.

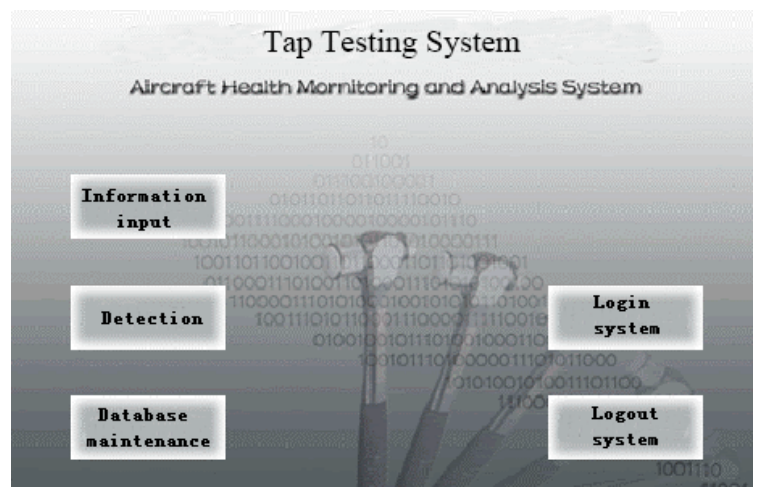

FIGURE VIII. SOFTWARE MAIN INTERFACE

\section{V.CONCLUSION}

In this paper, structure, characteristics, defects and damages types, sources and security of composite materials is studied Principle, tap hammer design, signal processing unit design, database construction and intelligent algorithm of intelligent tap testing is discussed. Finally, the intelligent tap testing system is proposed and the tap NDT software is designed on the basis of above theoretical research. The system can realize defects and damages identification of composite material.

\section{REFERENCES}

[1] Chen S J.Composite technology and large aircraft[J]. Acta Aeronautics et Astronautica Sinica, 2008,29(3):605-610.

[2] Ma B Q,Zhou Z G.Progress and development trends of composite structure evaluation using noncontact nondestructive testing techniques in aviation and aerospace industries[J].Acta Aeronautics et Astronautica Sinica,2014,35(7):1787-1803.

[3] Carden E P, Fanning P. Vibration based condition monitoring: a review[J]. Structural Health Monitoring,2004,3:355-377.

[4] Yan X D. Research on Intelligent Coin-Tap Test System of Aircraft Composite Structures[D].Nanjing: Nanjing University of Aeronautics and Astronautics,2007.

[5] Peng M Y.Research on Damage Mechanism of Aircraft Composite Material and Airworthiness Evaluation Technology[D].Nanjing: Nanjing University of Aeronautics and Astronautics,2008.

[6] Abou-Khousa M A, Ryley A, Kharkovsky S, et al. Comparison of X-ray, millimeter wave, shearography and through-transmission ultrasonic methods for inspection of honeycomb composites[J]. Review of Progress in Quantitative Nondestructive Evaluatiion ,2007 ,894(26):999-1006.

[7] Palmer S B, Dixon S. Industrially viable non-contact ultrasound[J].Insight, 2003,45(3):211-217. 